\title{
The association between early life lung function and wheezing during the first 2 yrs of life
}

\author{
S. Young, J. Arnott, P.T. O'Keeffe, P.N. Le Souef, L.I. Landau
}

\begin{abstract}
The association between early life lung function and wheezing during the first 2 yrs of life. S. Young, J. Arnott, P.T. O'Keeffe, P.N. Le Souef, L.I. Landau. (C) ERS Journals Ltd 2000. ABSTRACT: Reports have suggested that certain infants are predisposed to wheezing in the first 2 yrs of life due to abnormal lung function, prior to the first wheezing illness. The authors investigated the association between infant lung function and wheeze during the first 2 yrs of life.

A cohort of 253 infants was evaluated. Respiratory function assessment was performed at 1, 6, and 12 months of age. Parental history of asthma, atopy, and maternal antenatal smoking habits were recorded. An infant was identified as having wheezed on the basis of parental report and, where possible, physician diagnosis. One hundred and sixty infants $(63 \%)$ had complete diary and questionnaire information on wheeze available for analysis. Of these: 79 infants $(50 \%)$ had never wheezed (NW) during the first 2 yrs of life and 81 had reported wheeze (W) $(50 \%)$.

Of those with a report of wheeze, the distribution through the first 2 yrs of life was; 28 during the first year of life only (Y1), 21 in the second year of life only (Y2), and 32 wheezed in both the first and second years of life (Y1\&2).

At the age of 1 month, prior to any lower respiratory illness, the $W$ group had impaired lung function in comparison to the NW group. In Y1 infants, the neonatal lung function differences resolved by 12 months of age. In Y2 and Y1\&2 infants lung function differences persisted throughout the first year of life. Prevalence of parental asthma and maternal antenatal smoking was increased in the $W$ group $p=0.001$, $p=0.008$, respectively), in comparison to the NW infants. Maternal antenatal smoking prevalence was increased in the $\mathrm{Y} 2$ and $\mathrm{Y} 1 \& 2$ infants in comparison to the NW group $(p=0.04),(p=0.01)$, respectively.

Wheezing during the first year of life is often a transient condition which improves with time. It appears to be related to early life reduced small airway calibre. Wheezing that begins or persists into the second year of life is usually associated with a different abnormality of the airways. Commencement or persistence of wheeze into the second year of life may be part of the clinical entity recognized as asthma.

Eur Respir J 2000; 15: 151-157.
\end{abstract}

Retrospective studies investigating wheeze in older children and adolescents have identified the incidence of wheezing lower respiratory illness (LRIs) during the first 2 yrs of life as an important indicator of risk for symptoms and lung function abnormalities at an older age [1-3]. However, these studies were retrospective and did not have objective measurements of lung function during the first $2 \mathrm{yrs}$ of life. Therefore it was not possible to determine whether the lung function discrepancies documented at the time of study were present early in life. Recently, several reports have indicated that abnormal early life lung function, measured prior to any lower respiratory illness, is associated with subsequent wheezing in infancy and early childhood [4-9]. These reports suggest that certain infants are predisposed to wheezing and that the predominant risk factor for wheezing in the first 2 yrs of life is an abnormal baseline lung function, prior to the first wheezing illness, which may persist through childhood and adolescence. Some of these wheezing illnesses may be due to asthma.
Dept of Respiratory Medicine, Princess Margaret Hospital for Children, Perth, Western Australia, Australia.

Correspondence: L.I. Landau Faculty of Medicine and Dentistry The University of Western Australia Nedlands

WA 6907

Australia

Fax: 61893462369

Keywords: Early childhood wheeze infant airway responsiveness infant lung function

influence of maternal tobacco smoking influence of parental asthma

Received: February 221999 Accepted after revision September 281999

Supported by the National Health and Medical Research Council, Australia, (Project Numbers 880910 and 910160).
Two important questions have arisen from infant wheezing studies. The first is whether the pattern of wheezing during the first 2 yrs of life is important, is there a difference between those that wheeze in the first, second, or both years, or are all individuals who wheeze the same, regardless of the year in which the wheeze is experienced? The second question of interest is whether wheezing during the first 2 yrs of life is the clinical entity known as asthma.

In this report the authors aimed to: examine the relationship between early life lung function and wheezing during the first 2 yrs of life, and to investigate whether there were differences between individuals based on the year in which wheeze was experienced (first, second, or both).

\section{Subjects and methods}

The infants in this study were part of a prospective longitudinal study cohort which initially consisted of 253 
infants. The families of all infants were recruited between May 1987 and December 1991 as described previously [10]. Signed parental consent was obtained for all participating families. The study was performed with the approval of the medical ethics committees of Princess Margaret Hospital for Children and the University of Western Australia. The inclusion criteria for the infants were full term gestation ( $>36$ weeks), an absence of perinatal health problems, and no major congenital anomalies.

\section{Family history}

Information about the parental history of asthma, atopy (eczema, hayfever), and maternal antenatal smoking habits was obtained using a modified American Thoracic Society (ATS) questionnaire [11] administered by one of two investigators (S. Young, J. Arnott). Historical information was collected prior to the initial respiratory function assessment and was not known by the investigator responsible for lung function measurements during the respiratory assessment. A positive family history of asth$\mathrm{ma}$ and/or atopy was defined as doctor diagnoses in either or both parents. A positive smoking history was recorded when the mother reported having smoked during the pregnancy.

\section{Infant lung function}

Assessment of infant respiratory function included measurements of forced partial expiratory flow, airway responsiveness, passive lung mechanics, the pattern of tidal breathing, and arterial oxygen saturation $\left(\mathrm{Sa}_{2} \mathrm{O}_{2}\right)$. Measurements of respiratory function were made as close as possible to 1,6 , and 12 months of age. At the initial assessment none of the infants previously had a lower respiratory illness or any clinically important nonrespiratory illness. At the time of the repeat lung function assessments at ages 6 and 12 months, the infants were well, with none having an upper or lower respiratory tract infection in the preceding three weeks.

Partial forced expiratory flow-volume curves were obtained using the rapid thoracic compression technique (RTC) $[12,13]$.

Infants were studied while asleep after receiving chloral hydrate $\left(60-80 \mathrm{mg} \cdot \mathrm{kg}^{-1}\right)$. Lung function in infants has been shown to be unaffected by the administration of chloral hydrate [14-16]. Baseline maximum flow at functional residual capacity $\left(V^{\prime} \max , \mathrm{FRC}\right)$ was established after the administration of nebulized isotonic saline with an Airlife nebulizer (American Pharmaseal, Valencia, CA, USA), run at $6 \mathrm{~L} \cdot \mathrm{min}^{-1}$ from a compressed air source. This and all other nebulized agents were delivered directly into the face mask and inhaled during $1 \mathrm{~min}$ of tidal breathing. The mean of five forced tidal expirations was used as the baseline $V^{\prime} \max$,FRC reference value.

To assess airway responsiveness an infant histamine challenge was carried out as described previously [10, 13, $14,17]$. The provocative concentration of histamine producing a $40 \%$ fall in $V^{\prime} \max , F R C$ (PC40) was derived by linear interpolation from the plot of $\log$ histamine concentration against per cent fall in $V^{\prime}$ max,FRC from baseline. A PC40 represents a fall in $V^{\prime}$ max,FRC of greater than two standard deviations from the mean and is therefore representative of true airway response [13]. The coefficient of repeatability for an infant histamine challenge following this protocol is 3.3 sequentially doubled concentrations [18].

The time constant ( $t r \mathrm{rs})$, compliance $(C \mathrm{rs})$, and resistance $(R \mathrm{rs})$ of the total respiratory system were measured from a passive flow-volume slope after a single brief occlusion at end inspiration inducing the Herring-Breuer reflex [19]. $C_{\mathrm{rs}}$ was corrected for infant size by dividing by length (cm). Although this relationship is nonlinear and does not pass through the origin, this process of standardization does allow better comparison between groups.

The pattern of tidal breathing was assessed by measuring the timing ratio of the time to peak expiratory tidal flow to total expiratory flow time ( $t$ ptef $/ t$ E) [20]. This parameter has been shown to be able to detect airway disease in adults and infants $[5,20]$. This ratio was averaged from 10 consecutive breaths recorded at baseline.

$\mathrm{Sa}_{\mathrm{a}} \mathrm{O}_{2}$ was monitored throughout the study using a Nellcor N-200 E Pulse Oximeter (Nellcor Inc., Hayward, CA, USA) in beat to beat mode. The $\mathrm{Sa}_{\mathrm{a}} \mathrm{O}_{2}$ level post isotonic saline nebulization was taken as the baseline reference value. For each nebulization, $\mathrm{S}_{\mathrm{a}} \mathrm{O}_{2}$ was recorded immediately prior to and post administration with a change in $\mathrm{Sa}, \mathrm{O}_{2}$ being interpreted as the maximum change of postnebulization level from the prenebulization level. The lowest $\mathrm{Sa}, \mathrm{O}_{2}$ value reached was recorded and was observed to occur rapidly, that is, well within the first 1-2 min of inhalation. $\mathrm{Sa}_{\mathrm{a}} \mathrm{O}_{2}$ was monitored throughout the rapid thoracic compression manoeuvres and no effect of forced expiration on $\mathrm{Sa}, \mathrm{O}_{2}$ was observed. Supplemental oxygen was administered if $\mathrm{Sa}_{2} \mathrm{O}_{2}$ fell below $90 \%$.

\section{Infant health}

During the first year of life a weekly infant diary record was completed by the parents and included information on breast or bottle feeding, the presence of cough and/or wheeze, and the occurrence of any doctor diagnosed respiratory and/or atopic illness. At the age of 2 yrs a modified ATS questionnaire [11] detailing the child's health over the last year was completed by the parents for the families who were still contactable.

\section{Wheeze}

From the weekly diary records and $2 \mathrm{yr}$ follow-up questionnaire, an infant was identified as having wheezed on the basis of a parental report and, where possible, doctor diagnosis (community based general practitioner, private paediatrician, or hospital based paediatrician). From the diary records and the questionnaire the year, or years, in which wheeze was experienced was ascertained (first, second, or both).

\section{Infant group comparisons}

One hundred and sixty infants had complete diary information on the history of wheeze during the first 2 yrs of life. The infants were initially divided into two history groups, never wheezed (NW), infants who had no report of 
wheezing at any time during the first 2 yrs of life and wheezed (W), infants who had a report of wheezing at any time during the first 2 yrs of life (first, second, or both years). The infants were then subdivided into four groups: never wheezed (NW); wheeze in year 1 only (Y1), infants with a report of wheeze in the first year of life only; wheeze in year 2 only (Y2), infants with a report of wheeze in the second year of life only; wheeze in years 1 and 2 (Y1\&2), infants with a report of wheeze in both of the first $2 \mathrm{yrs}$ of life.

\section{Statistics}

Comparisons of the prevalence of parental asthma, atopy, and maternal smoking between the infant wheeze groups were made using Chi-squared analysis. Descriptive anthropometric data at each infant assessment was compared between the NW and W groups using the Student's unpaired t-test. To compare sexes and the four infant groups NW, Y1, Y2, Y1\&2, parametric analysis of variance and Student's unpaired t-test were used. The KruskalWallis test was used to determine if there was a difference between the infant groups at each age for lung function measurements. Where differences were indicated, the Mann-Whitney U-test was used to identify comparisons of significance. Analysis of $V^{\prime} \max , F R C$ included absolute and size corrected (infant length $(\mathrm{cm})$ ) flow. PC40 levels were normalized by $\log$ transformation and between group comparisons made by parametric analysis of variance and the Student's unpaired t-test.

\section{Results}

Of the 160 for whom complete diary and questionnaire information was available, $79(50 \%)$ had never wheezed during the first 2 yrs of life and 81 had reported wheeze $(50 \%)$. Of those with a report of wheeze, the distribution through the first 2 yrs of life was; 28 (35\%) during the first year of life only (Y1), $21(26 \%)$ in the second year of life only (Y2), and $32(39 \%)$ wheezed in both the first and second years of life (Y1\&2).

\section{Never wheezed versus ever wheezed}

Anthropometric characteristics for the two infant groups, at each of the assessment ages, were not different between those that did or did not wheeze during the first 2 yrs of life for age at the time of study, or birth weight. At the age of 1 month, there was a tendency for the $\mathrm{W}$ group to be heavier and longer at the time of study than the NW group $(p=0.08),(p=0.07)$, respectively). These size differences were not observed at 6 or 12 months of age.

Those infants who had wheezed at any time during the first 2 yrs of life had an increased prevalence of parental asthma (54\% versus $28 \%)(\mathrm{p}=0.001)$, and maternal antenatal smoking ( $40 \%$ versus $20 \%, \mathrm{p}=0.008)$. There was no difference between the two infant groups for the family history prevalence of atopy (eczema, hayfever).

At the age of 1 month, prior to any report of wheeze, infants who subsequently wheezed (W) had reduced absolute and size corrected flows $\left(86.2 \mathrm{~mL} \cdot \mathrm{s}^{-1}\right.$ (SEM 4.7)), $\left(1.57 \mathrm{~mL} \cdot \mathrm{s}^{-1} \cdot \mathrm{cm}^{-1}\right.$ (SEM 0.09$)$ ) in comparison to the NW infants $\left(104.6 \mathrm{~mL} \cdot \mathrm{s}^{-1}(\mathrm{SEM} 4.8 ; \mathrm{p}=0.005),\left(1.92 \mathrm{~mL} \cdot \mathrm{s}^{-1} \cdot \mathrm{cm}^{-1}\right.\right.$
(SEM 0.09; $\mathrm{p}=0.004)$. These flow measurement differences observed at 1 month of age, persisted at 6 months: $\mathrm{W}, 141.3 \mathrm{~mL} \cdot \mathrm{s}^{-1}\left(\mathrm{SEM}\right.$ 8.2; $=0.003,2.10 \mathrm{~mL} \cdot \mathrm{s}^{-1} \cdot \mathrm{cm}^{-1}$ (SEM 0.12; $\mathrm{p}=0.003$ ); NW, $170.5 \mathrm{~mL} \cdot \mathrm{s}^{-1}$ (SEM 7.8), 2.52 $\mathrm{mL} \cdot \mathrm{s}^{-1} \cdot \mathrm{cm}^{-1}$ (SEM 0.11 ), respectively. At 12 months of age, a trend remained for the $\mathrm{W}$ group to have lower absolute and size corrected flows $\left(180.1 \mathrm{~mL} \cdot \mathrm{s}^{-1}\right.$ (SEM 7.5)), (2.38 $\mathrm{mL} \cdot \mathrm{s}^{-1} \cdot \mathrm{cm}^{-1}$ (SEM 0.10)), respectively, in comparison to the NW infants $\left(212.3 \mathrm{~mL} \cdot \mathrm{s}^{-1}\right.$ (SEM 12.5) $\left.(\mathrm{p}=0.07)\right),(2.85$ $\mathrm{mL} \cdot \mathrm{s}^{-1} \cdot \mathrm{cm}^{-1}($ SEM 0.17$\left.)(\mathrm{p}=0.06)\right)$, respectively.

The level of airway responsiveness at the age of 1 month was increased in the $\mathrm{W}$ group $\left(0.65 \mathrm{~g} \cdot \mathrm{L}^{-1}\right)$ in comparison to the NW infants $\left(1.48 \mathrm{~g} \cdot \mathrm{L}^{-1}\right)(\mathrm{p}=0.008)$. There were no differences between the two infant groups for the level of airway responsiveness at 6 or 12 months.

Assessment of passive lung mechanics indicated that throughout the first year of life, there were no differences between the two infant groups.

No differences were found in $t \mathrm{ptef} / t \mathrm{E}$ between the NW and $\mathrm{W}$ infants, at any age.

At the age of 1 month, the level of $\mathrm{Sa}_{\mathrm{a}} \mathrm{O}_{2}$ was observed to be different between the two infant groups $(\mathrm{p}=0.01)$. The W infants had a small but significantly lower mean $\mathrm{Sa}_{\mathrm{a}} \mathrm{O}_{2}$ $(98.1 \%$ (SD 2.1)) in comparison to the NW infants $(98.8 \%$ (SD 1.8)). This difference in $\mathrm{Sa}_{2} \mathrm{O}_{2}$ was not seen at any other assessment age.

Never wheezed versus the year of reported wheeze groups

Anthropometric characteristics for the four infant groups, were not different for mean birth weight or the mean age of study at each of the three assessments. At the 1 month assessment, a difference in study weight was observed $(\mathrm{p}=0.04)$, with the $\mathrm{Y} 1$ infants being heavier $(5.26 \mathrm{~kg}$ (SD 0.74)) than the NW (4.80 kg (SD 0.63; p=0.004), Y2 (4.89 kg (SD 0.64; $\mathrm{p}=0.05)$, and Y1\&2 infants (4.85 kg (SD $0.83 ; \mathrm{p}=0.05$ ). A similar pattern was observed between the infant groups for length at the time of the first assessment $(\mathrm{p}=0.03)$ with the $\mathrm{Y} 1$ infants being longer $(56.3 \mathrm{~cm}$ (SD 2.6)) than the NW (54.6 cm (SD 2.5; $\mathrm{p}=0.003)$, and Y1\&2 infants $(54.7 \mathrm{~cm}$ (SD 3.2; $\mathrm{p}=0.05)$. These study weight and length differences were not observed at any other assessment age.

Compared to the NW group (20\%), the Y2 (48\%) and Y1\&2 (48\%) infants had an increased prevalence of maternal antenatal smoking $(\mathrm{p}=0.04, \mathrm{p}=0.01$, respectively). The Y2 and Y1\&2 groups also had an increased prevalence of maternal smoking in comparison to the Y1 infants, $(\mathrm{p}=0.07, \mathrm{p}=0.05$, respectively). The prevalence of a parental history of asthma was increased in Y1 $(56 \%)$, Y2 $(52 \%)$, and Y1\&2 infants $(54 \%)$ in comparison to the NW group $(31 \%),(p=0.01, p=0.05),(p=0.01$, respectively). There were no intergroup differences in prevalence for the parental history of atopy (hayfever, eczema).

At the age of 1 month, prior to any wheeze, mean baseline absolute and size corrected $V^{\prime} \max , F R C$ was different between the infant groups. In comparison to the NW group $\left(104.6 \mathrm{~mL} \cdot \mathrm{s}^{-1}(\mathrm{SEM} 4.8)\right)$, the Y1 $\left(84.7 \mathrm{~mL} \cdot \mathrm{s}^{-1}\right.$ (SEM 10.3)), Y2 $\left(89.6 \mathrm{~mL} \cdot \mathrm{s}^{-1}(\mathrm{SEM} \mathrm{8.4)})\right.$, and Y1\&2 $\left(85.4 \mathrm{~mL} \cdot \mathrm{s}^{-1}(\mathrm{SEM}\right.$ 6.4)) infants had lower absolute flows ( $\mathrm{p}=0.03, \mathrm{p}=0.08, \mathrm{p}=$ 0.04 , respectively). Size corrected $V^{\prime} \max$,FRC for all the wheeze groups, were reduced in comparison to the NW group. 
Table 1. - Physician diagnosis of asthma in infants with reported wheeze during the first 2 yrs of life

\begin{tabular}{lccc}
\hline Group & $\mathrm{n}$ & Asthma year 1 & Asthma year 2 \\
\hline NW & 79 & $2(2)$ & $3(4)$ \\
Y1 & 28 & $1(4)$ & $2(7)$ \\
Y2 & 21 & $0(0)$ & $13(62)$ \\
Y1\&2 & 32 & $4(14)$ & $13(45)$ \\
\hline
\end{tabular}

Data are presented as absolute numbers of infants, with percentage in parentheses. Asthma year 1: doctor diagnosis of asthma during the first year of life; Asthma year 2: doctor diagnosis of asthma during the second year of life; NW: infants who had no report of wheezing at any time during the first 2 yrs of life; Y1: infants with a report of wheeze in the first year of life only; Y2: infants with a report of wheeze in the second year of life only; Y1\&2: infants with a report of wheeze in both of the first 2 yrs of life.

At 6 months of age, mean absolute $V^{\prime}$ max,FRC was again different between the infant groups $(\mathrm{p}=0.01)$ with Y2 $\left(138.0 \mathrm{~mL} \cdot \mathrm{s}^{-1}\right.$ (SEM 13.5)) and Y1\&2 infants $\left(134.3 \mathrm{~mL} \cdot \mathrm{s}^{-1}\right.$ (SEM 14.3)) having a reduced absolute $V^{\prime} \max , F R C$ in comparison to the $\mathrm{NW}$ group $\left(170.5 \mathrm{~mL} \cdot \mathrm{s}^{-1}\right.$ (SEM 7.8)), $(\mathrm{p}=$ $0.04, \mathrm{p}=0.003$, respectively). A similar pattern was evident for size corrected $V^{\prime}$ max,FRC.

At 12 months of age absolute flow was reduced in Y1\&2 infants $\left(161.8 \mathrm{~mL} \cdot \mathrm{s}^{-1}\right.$ (SEM 10.5)), in comparison to the NW group $\left(212.3 \mathrm{~mL} \cdot \mathrm{s}^{-1}\right.$ (SEM 12.5; $\left.\mathrm{p}=0.04\right)$ and $\mathrm{Y} 1$ infants $\left(195.8 \mathrm{~mL} \cdot \mathrm{s}^{-1}\right.$ (SEM 11.5; $\left.\mathrm{p}=0.03\right)$. A reduced size corrected flow was also observed for Y1\&2 infants.

The level of airway responsiveness at the age of 1 month was different between the infant groups $(p=0.04)$, with Y2 infants identified as having increased responsiveness $(0.87$ $\left.\mathrm{g} \cdot \mathrm{L}^{-1}\right)$ in comparison to the NW group $\left(2.04 \mathrm{~g} \cdot \mathrm{L}^{-1}\right)$. This increased airway responsiveness to inhaled histamine was not observed at any other age amongst the infant groups.

Evaluation of passive lung mechanics showed that size corrected $C \mathrm{rs}$ was different between the infant groups at the age of 1 month $(\mathrm{p}=0.02)$. Y1 infants had an increased $C \mathrm{rs}$ $\left(1.65\left(\mathrm{~mL} \cdot \mathrm{cmH}_{2} \mathrm{O}^{-1}\right) \cdot \mathrm{kg}^{-1}\right.$ (SEM 0.08)) in comparison to the NW (1.51 mL.cmH $\left.\mathrm{O}^{-1}\right) \cdot \mathrm{kg}^{-1}$ (SEM 0.05; $\left.\mathrm{p}=0.08\right)$ ), Y2 $\left(1.41\left(\mathrm{~mL} \cdot \mathrm{cmH}_{2} \mathrm{O}^{-1}\right) \cdot \mathrm{kg}^{-1}\right.$ (SEM 0.08); $\left.\left.\mathrm{p}=0.03\right)\right)$, and $\mathrm{Y} 1 \& 2$ infants $\left(1.34 \mathrm{~mL} \cdot \mathrm{cmH}_{2} \mathrm{O}^{-1}\right) \cdot \mathrm{kg}^{-1}$ (SEM 0.08); $\left.\mathrm{p}=0.004\right)$ ). There was a trend for Y1\&2 infants to also have a reduced $C_{\text {rs }}$ in comparison to the NW group $(\mathrm{p}=0.07)$. Size corrected $C$ rs was not different between the infant groups at 6 or 12 months of age.

Baseline $t \mathrm{ptef} / \mathrm{t}$ E was not different between any of the infant groups at any age.

An unexpected finding was that $\mathrm{Sa}_{\mathrm{a}} \mathrm{O}_{2}$ at the age of 1 month, was different between the infant groups $(\mathrm{p}=0.04)$, with the Y1 infants having a trend towards a lower $\mathrm{Sa}_{\mathrm{a}} \mathrm{O}_{2}$ (97.9\% (SD 2.4)) than the NW group (98.8\% (SD 1.8)), $(\mathrm{p}=0.07)$ and $\mathrm{Y} 2$ infants having a lower $\mathrm{Sa}_{\mathrm{a}} \mathrm{O}_{2}(97.5 \%$ (SD $2.5)$ than the NW infants $(\mathrm{p}=0.02)$. No $\mathrm{Sa}_{\mathrm{a}} \mathrm{O}_{2}$ differences were observed amongst the infant groups at any other age.

\section{The influence of sex}

Analysis of the role of infant sex was restricted to the NW and W groupings, as small sample sizes resulted from dividing the infant cohort into sex and year of wheeze.
At the age of 1 month, $\mathrm{W}$ females had a reduced absolute and size corrected $V^{\prime}$ max,FRC $(86.7 \mathrm{~mL} \cdot \mathrm{s}-1$ (SEM 9.1)) in comparison to the NW females $\left(112.5 \mathrm{~mL} \cdot \mathrm{s}^{-1}\right.$ (SEM 6.8); $\mathrm{p}=0.01$ ). There were no differences in absolute flow observed amongst the male infants. In addition, NW males had a reduced size corrected $V^{\prime} \max$, FRC in comparison to the NW females $(\mathrm{p}=0.05)$.

At 6 months of age, $\mathrm{W}$ females again had a reduced absolute flow $\left(140.0 \mathrm{~mL} \cdot \mathrm{s}^{-1}\right.$ (SEM 13.1)) and size corrected flow $\left(2.11 \mathrm{~mL} \cdot \mathrm{s}^{-1} \cdot \mathrm{cm}^{-1}\right.$ (SEM 0.20)) in comparison to the NW females (181.6 mL. $\mathrm{s}^{-1}$ (SEM 10.1); $\left.\mathrm{p}=0.004\right),(2.68$ $\mathrm{mL} \cdot \mathrm{s}^{-1} \cdot \mathrm{cm}^{-1}$ (SEM 0.14); $\left.\mathrm{p}=0.006\right)$. At 12 months of age, there was a tendency for $\mathrm{W}$ males to have a reduced size corrected flow $\left(2.24 \mathrm{~mL} \cdot \mathrm{s}^{-1} \cdot \mathrm{cm}^{-1}\right.$ (SEM 0.13)) in comparison to the $\mathrm{W}$ females $\left(2.60 \mathrm{~mL} \cdot \mathrm{s}^{-1} \cdot \mathrm{cm}^{-1}\right.$ (SEM 0.17); $\left.\mathrm{p}=0.08\right)$.

At the age of 1 month, an increased sensitivity to inhaled histamine was observed for the $\mathrm{W}$ females $\left(1.07 \mathrm{~g} \cdot \mathrm{L}^{-1}\right)$ in comparison to the NW females $\left(2.52 \mathrm{~g} \cdot \mathrm{L}^{-1}\right)(\mathrm{p}=0.004)$. There were no differences in the level of airway responsiveness within the male groups or between the sexes at this age. The level of airway responsiveness was not different amongst the infant groups at 6 or 12 months of age.

Baseline passive lung mechanics were not different amongst the infant sex groups at any assessment during the first year of life.

At 1 month of age, $\mathrm{Sa}, \mathrm{O}_{2}$ was lower for $\mathrm{W}$ males $(98.0 \%$ (sD 2.3)) in comparison to the NW males (99.3\% (SD 1.2); $(\mathrm{p}=0.01)$. This lower $\mathrm{Sa}_{\mathrm{a}} \mathrm{O}_{2}$ between $\mathrm{W}$ and $\mathrm{NW}$ males was not observed at any other age and no between sex differences were noted at any assessment.

The association between wheeze and a physician diagnosis of asthma

This analysis was restricted to the year of wheeze infant grouping, as the authors wished to determine whether a diagnosis of asthma was more likely to be diagnosed based on the year(s) in which wheeze was reported (table 1).

In the first year of life, the Y1\&2 group had the highest incidence of the diagnosis of asthma (14\%) in comparison to the NW (2\%), Y1 (4\%), and Y2 $(0 \%)$ groups. However, during the second year of life the Y2 infants had the highest incidence of the diagnosis of asthma $(62 \%)$ in comparison to the NW (4\%), Y1 (7\%), and Y1\&2 (45\%). Interestingly, it was noted that asthma was diagnosed in a small number of infants who had no report of wheeze at any time during the first 2 yrs of life.

Table 2 summarizes the differences identified between the NW and $\mathrm{W}$ infants, and the NW, Y1, Y2, and Y1\&2 groups.

\section{Discussion}

This study provides further supportive evidence that early life lung function abnormalities are associated with the development of wheeze in early childhood and are present prior to the first wheezing episode. The uniqueness of this study lies with the prospective, longitudinal evaluation of early life respiratory function and airway responsiveness on the basis of the year in which wheeze was experienced. The study has demonstrated differences in lung function between those who wheeze only in the first 
Table 2. - Summary characteristics, at the mean age of 1 month, of infants who subsequently wheezed during the first 2 yrs of life in comparison to those that never wheezed

\begin{tabular}{|c|c|c|c|c|}
\hline & $\mathrm{n}$ & Family history* & Anthropometric measures* & Respiratory function* \\
\hline $\mathrm{W}$ & 81 & $\begin{array}{ll}\uparrow & \text { Parental asthma } \\
\uparrow & \text { Maternal smoking }\end{array}$ & $\begin{array}{l}\uparrow \text { Study weight } \\
\uparrow \text { Study length }\end{array}$ & $\begin{aligned} \downarrow & V^{\prime} \max , \mathrm{FRC} \\
& \mathrm{AHR} \\
& \mathrm{S}_{\mathrm{a}, \mathrm{O}_{2}}\end{aligned}$ \\
\hline Y1 & 28 & $\uparrow$ Parental asthma & $\begin{array}{l}\uparrow \text { Study weight } \\
\uparrow \text { Study length }\end{array}$ & $\begin{array}{cc}\downarrow & V^{\prime} \max , \mathrm{FRC} \\
& \uparrow \mathrm{Crs} \\
\downarrow & \mathrm{Sa}_{\mathrm{a}, \mathrm{O}_{2}}\end{array}$ \\
\hline Y2 & 21 & $\begin{array}{ll}\uparrow & \text { Parental asthma } \\
\uparrow & \text { Maternal smoking }\end{array}$ & & $\begin{array}{cc}\downarrow & V^{\prime} \max , \mathrm{FRC} \\
& \uparrow \mathrm{AHR} \\
& \downarrow \mathrm{Sa}_{\mathrm{a}, \mathrm{O}_{2}}\end{array}$ \\
\hline $\mathrm{Y} 1 \& 2$ & 32 & $\begin{array}{ll}\uparrow & \text { Parental asthma } \\
\uparrow & \text { Maternal smoking }\end{array}$ & & $\begin{array}{c}\downarrow V_{\text {max,FRC }}^{\prime} \\
\downarrow C_{\mathrm{rs}}\end{array}$ \\
\hline
\end{tabular}

*: $\uparrow$ increased in comparison to infants who never wheezed, and $\downarrow$, reduced in comparison to infants who never wheezed. $V^{\prime}$ max,FRC: maximum flow at functional residual capacity; AHR: airway hyperresponsiveness; $S \mathrm{a}, \mathrm{O}_{2}$ : arterial oxygen saturation; $C$ rs: compliance of the total respiratory system. For further abbreviations see table 1 .

year of life in comparison to those infants who either recurrently wheeze throughout the first 2 yrs of life or who commence wheezing in their second year. The increased weight and length at 1 month of those infants with subsequent wheezing may provide supportive evidence of in utero events producing the developmental anomalies predisposing to wheezing.

It has been proposed that the risk of wheezing in infancy is increased, in comparison with older age groups, by smaller absolute size of the airways, a reduction in elastic recoil pressure of the lung, and a highly compliant chest wall [5]. The smaller airway calibre could be due to anatomical differences, subclinical inflammation or increased airway wall compliance. Infants with a greater reduction in airway calibre, as reflected by reduced lung function, could be expected to be at an increased risk of wheezing. Furthermore, it has been widely suggested that during infancy, a viral respiratory infection will induce additional narrowing of peripheral airways and therefore, result in wheeze in those individuals that already have preexisting reduced airway calibre.

Clinical practice supports these hypotheses as, during the first year of life, wheezing LRIs are a significant cause of respiratory morbidity requiring hospitalization. In this study, Y1\&2 infants were shown to have a persistently reduced baseline flow throughout the first 12 months of life in comparison to NW infants. Of particular importance was the demonstration that the flow abnormality was present as early as 1 month of age and prior to any lower respiratory infection.

Although wheezing LRI's are common during the first year of life, their contribution to early childhood morbidity after the age of $1 \mathrm{yr}$ is significantly reduced. The study observed that the abnormal lung function observed in those infants who wheezed only during the first year of life improved within 12 months, however, persistent small airway dysfunction was a feature of those who wheezed in the second year of life. These data support the hypothesis that a significant portion of the wheeze experienced by infants in the first year of life is most likely triggered by viral respiratory infections in those with transiently reduced airway calibre and increased $C$ rs. The persistence of lung function abnormalities in those who wheeze beyond year one is suggestive of a different disease process, possibly early inflammation.

Several other studies have assessed abnormal infant lung function in association with wheeze $[4,5,7,8,21,22]$. In a prospective cohort study of healthy infants, MARTINEz et al. [5] reported that $t \mathrm{ptef} / \mathrm{tE}$, an indirect measure of airway conductance, in the neonatal period was predictive of subsequent wheeze during the first year of life. Follow-up of this cohort indicated that wheeze during the first 3 yrs of life was still associated with a reduced neonatal $t \mathrm{ptef} / t \mathrm{E}$. However, infants that started to wheeze during the second year of life were shown to have a reduced $V^{\prime} \max$, FRC at 1 month of age [7]. Assessment of this cohort at the age of 6 yrs indicated that infants who had wheeze before the age of 3 yrs but not at the age of 6 yrs had a reduced size corrected $V^{\prime}$ max,FRC during the first year of life. However, infants who experienced wheeze both at 1 and 6 yrs of age, had normal size corrected flows in infancy but not at the age of 6 yrs [8]. CLARKE et al. [4] measured $V^{\prime}$ max,FRC in the neonatal period and found no predictive association between early life $V^{\prime}$ max,FRC and subsequent wheeze. However, these investigators showed that size corrected $V^{\prime}$ max,FRC was reduced at the age of 6 months in infants who had previously experienced wheeze in comparison to asymptomatic infants [21]. Two other studies have also measured $V^{\prime}$ max,FRC in wheezy and nonwheezy infants and both have shown a reduced baseline flow in infants who wheeze $[21,22]$, however, these studies did not assess lung function prior to wheeze.

In addition, two previous reports from this cohort have shown neonatal lung function abnormalities preceding the onset of a wheezing LRI $[23,24]$. The current authors demonstrated the predictive power of the presence of flow limitation during tidal expiration, at the age of 1 month, for the development of a wheezing illness diagnosed as asthma by the age of 2 years [23]. Secondly, the authors reported that infants who experienced bronchiolitis had lung function abnormalities, in the neonatal period, prior to the bronchiolitic episode [24]. These were important observations, as it was previously unknown whether the lung function abnormalities documented during and/or after an episode of wheezing were due to the acute illness or preceded the event. 
The role of airway responsiveness in the development of wheeze is unclear. It is not known whether increased responsiveness is due to small airway calibre or early inflammation. It is possibly both. However, in this study the measurement can be used to compare groups of infants. At the age of 1 month, prior to any wheeze, airway responsiveness was increased in infants who subsequently experienced wheeze at some time during the first 2 yrs of life. On further analysis, it was found that infants who began to wheeze only in the second year of life had increased airway responsiveness at the age of 1 month. In addition, the level of airway responsiveness was not different in those who wheezed during the first year of life only. PRENDIVILLE et al. [25] demonstrated sensitivity to inhaled histamine in a group of recurrently wheezy infants, however, as no control group was assessed it was not possible to determine whether the observed level of airway responsiveness in the wheezy infants differed from that of infants who did not wheeze. The lack of association between airway responsiveness and current wheeze has also been demonstrated by STICK et al. [22]. These investigators assessed lung function and airway responsiveness to methacholine in recurrently wheezy infants and infants who had never wheezed. No difference in the level of methacholine responsiveness between the infant groups was observed. In a study of symptomatic and asymptomatic infants at the age of 6 months, Clarke et al. [21] also showed no difference in $\mathrm{PC} 30$ between the two infant groups. Although these previous studies $[21,22,25]$ provided useful information about the infant respiratory function in recurrently wheezy infants, all the studies assessed airway responsiveness subsequent to the onset of wheezing. In a prospective study of healthy infants, ClaRke et al. [4] have demonstrated no overall predictive association of PC40 assessed in the neonatal period, with subsequent wheeze. The infant inclusion criteria used by these investigators was a positive history of parental atopy and the cohort did not include a control group of infants who had a negative parental atopic history. This cohort composition may explain the overall lack of association between neonatal airway responsiveness and subsequent wheeze. Interestingly, these authors did report that female infants who subsequently wheezed had an increased sensitivity to histamine in comparison to females who did not wheeze. No such difference was present amongst male infants. This observation concurs with the current results.

The association between infant sex, lung function, and wheeze is also unclear. Male infants wheeze more frequently than female infants [26-28] and this has been explained by male infants having smaller airways relative to lung size in comparison to females [29, 30]. Some demonstrate that a particular sex has higher flows in comparison to the other sex $[15,31]$, whilst other investigators have not observed any difference between male and female infants $[12,32,33]$. The current authors found that, at the age of 1 and 6 months, males who never wheezed had lower flows than females who never wheezed. In addition, female infants who subsequently wheezed had a reduced flow and increased airway responsiveness compared with females who did not wheeze. Furthermore, among those who had wheezed, males had a lower flow than females. MARTinez et al. [5] also reported, that in early life, female (not male) infants who subsequently wheezed during the first year of life had reduced flow. However, another study did not find a sex association with lung function and wheezing in the first 3 yrs of life [7]. Some have argued that exposure to tobacco smoke during pregnancy may lead to "masculinization" of the female foetus. These data suggest such a process in lung development. Clarke et al. [4], however, identified a trend for male, not female, infants, who subsequently wheezed, to have a lower flow.

Sparse information is available on the association of sex and airway responsiveness. The current study found that at the age of 1 month, females who subsequently wheezed had increased sensitivity to inhaled histamine in comparison to females who did not experience wheeze. This observation has also been reported by CLARKE et al. [4].

A lower level of $S \mathrm{a}, \mathrm{O}_{2}$ at the age of 1 month was found in infants who subsequently wheezed at any time compared to infants who did not go on to wheeze. This observation has not previously been reported. Further analysis indicated that the reduced $\mathrm{Sa}_{\mathrm{a}} \mathrm{O}_{2}$ was restricted to male infants alone. The mechanism for this observation is not known.

The question as to whether the wheezing experienced in the first 2 yrs of life represents the clinical entity of asthma is unresolved. This study was able to document the number of infants that received a doctor diagnosis of asthma in the first and/or second years of life in relation to the year(s) in which wheeze was reported.

\section{Speculation}

The data suggest that wheeze in the first year of life only, may be due primarily to viral respiratory illnesses in predisposed infants rather than asthma; the majority of wheeze that starts in the second year of life is attributable to asthma; and wheeze experienced in both years may be a mix of viral respiratory illness and asthma.

The results of this study suggest that wheezing during the first year of life is often a transient condition which may be due to early life reduced small airway calibre which improves with time. An increase in airway size and lung recoil with growth during the first year could result in normalization of resistance and compliance of the total respiratory system and therefore, decrease the likelihood of wheeze, particularly in the presence of a viral respiratory infection. Wheezing that begins or persists into the second year of life appears to be the result of a different process, as it is associated with continuing abnormality of the airways, as indicated by persistent reduced flow throughout the first year of life, increased airway responsiveness, and decreased compliance of the respiratory system. The authors suggest that wheezing that begins or persists into the second year of life is more likely to be part of the clinical entity recognized as asthma.

Acknowledgements. The authors wish to acknowledge the invaluable contributions of all of the participating families, the staff of the antenatal clinic at Osborne Park Hospital, and D. Turner, A. Reese, G. Geelhoed, S. Stick, and J. Henderson. 


\section{References}

1. Gold DR, Tager IB, Weiss S, et al. Acute lower respiratory illness in childhood as a predictor of lung function and chronic respiratory symptoms. Am Rev Respir Dis 1989; 140: 877-884.

2. Strope GL, Stewart PW, Henderson FW, Ivins SS, Stedman HC, Henry MM. Lung function in school-age children who had mild lower respiratory illness in early childhood. Am Rev Respir Dis 1991; 144: 655-662.

3. Voter KZ, Henry MM, Stewart PW, Henderson FW. Lower respiratory illness in early childhood and lung function and bronchial reactivity in adolescent males. $\mathrm{Am}$ Rev Respir Dis 1988; 137: 302-307.

4. Clarke JR, Salmon B, Silverman M. Bronchial responsiveness in the neonatal period as a risk factor for wheezing in infancy. Am J Respir Crit Care Med 1995; 151: 1434-1440.

5. Martinez FD, Morgan WJ, Wright AL, Holberg CJ, Taussig LM. Diminished lung function as a predisposing factor for wheezing respiratory illness in infants. $N$ Engl $J$ Med 1988; 319: 1112-1117.

6. Martinez FD, Antognini G, Macri F, et al. Parental smoking enhances bronchial responsiveness in nine-yearold children. Am Rev Respir Dis 1988; 138: 518-523.

7. Martinez FD, Morgan WJ, Wright AL, Holberg C, Taussig LM, and the Group Health Medical Associates. Initial airway function is a risk factor for recurrent wheezing respiratory illnesses during the first three years of life. Am Rev Respir Dis 1991; 143: 312-316.

8. Martinez FD, Wright AL, Taussig LM, Holberg CJ, Halonen M, Morgan WJ. Asthma and wheezing in the first six years of life. $N$ Engl J Med 1995; 332: 133-138.

9. Tager IB, Hanrahan JP, Tosteson TD, et al. Lung function, pre- and post-natal smoke exposure, and wheezing in the first year of life. Am Rev Respir Dis 1993; 147: 811-817.

10. Young S, Le Souef PN, Geelhoed GC, Stick SM, Landau LI. The influence of a family history of asthma and parental smoking on the level of airway responsiveness in infants soon after birth. N Engl J Med 1991; 324: 1168 1173 .

11. Ferris BG. Epidemiology standardization project: II, recommended respiratory disease questionnaires for use with adults and children in epidemiological research. $A m$ Rev Respir Dis 1978; 118 (Suppl. V6): 7-53.

12. Taussig LM, Landau LI, Godfrey S, Arad I. Determinants of forced expiratory flow in newborn infants. $J \mathrm{Appl}$ Physiol 1982; 53: 1220-1227.

13. Le Souef PN, Geelhoed GC, Turner DJ, Morgan SEG, Landau LI. Response of normal infants to inhaled histamine. Am Rev Respir Dis 1989; 139: 62-66.

14. Silverman M, Prendiville A, Green S. Partial expiratory flow-volume curves in infancy: technical aspects. Bull Eur Physiopathol Respir 1986; 22: 257-262.

15. Tepper RS, Morgan WJ, Cota K, Wright A, Taussig LM, and GHMA Pediatricians. Physiologic growth and development of the lung during the first year of life. Am Rev Respir Dis 1986; 134: 513-519.

16. Turner DJ, Morgan SEG, Landau LI, Le Souef PN. Methodological aspects of flow-volume studies in infants. Pediatr Pulmonol 1990; 8: 289-293.
17. Cockcroft DW. Measurements of airway responsiveness to inhaled histamine or methacholine: method of continuous aerosol generation and tidal breathing inhalation. In : Hargreave FE, Woolcock AJ, eds. Airway hyperresponsiveness. Measurement and interpretation. Mississauga, Ontario, Canada, Astra, 1985; pp. 22-28.

18. Stick SM, Turner DJ, Landau LI, Le Souef PN. Histamine challenge tests in infants: repeatability and comparison with methacholine. Am Rev Respir Dis 1990; 141: Suppl. V4: A283.

19. Le Souef PN, England SJ, Bryan AC. Passive respiratory mechanics in newborns and children. Am Rev Respir Dis 1984; 129: 552-556.

20. Morris MT, Lane DJ. Tidal expiratory flow patterns in airflow obstruction. Thorax 1981; 36: 135-142.

21. Clarke JR, Reese A, Silverman M. Bronchial responsiveness and lung function in infants with lower respiratory tract illness over the first six months of life. Arch Dis Child 1992; 67: 1454-1458.

22. Stick SM, Arnott J, Turner DJ, Young S, Le Souef PN, Landau LI. Bronchial responsiveness and lung function in recurrently wheezy infants. Am Rev Respir Dis 1991; 144: 1012-1015.

23. Young S, Arnott J, Le Souef PN, Landau LI. Flow limitation during tidal expiration in symptom-free infants and the subsequent development of asthma. $J$ Pediatr 1994; 124: 681-688.

24. Young S, O'Keeffe PT, Arnott J, Landau LI. Infant lung function, airway responsiveness, and respiratory symptoms before and after bronchiolitis. Arch Dis Child 1995; 72: 16-24.

25. Prendiville A, Green S, Silverman M. Bronchial responsiveness to histamine in wheezy infants. Thorax 1987; 42: 92-99.

26. Wright AL, Taussig LM, Ray CG, Harrison HR, Holberg CJ. The Tucson children's respiratory study. II. Lower respiratory tract illness in the first year of life. $A m J$ Epidemiol 1989; 129: 1232-1246.

27. Horwood LJ, Fergusson DM, Shannon FT. Social and familial factors in the development of early childhood asthma. Pediatrics 1985; 75: 859-868.

28. Phelan PD, Landau LI, Olinsky A. Epidemiology of acute respiratory infections. In: Respiratory illness in children. Oxford, UK, Blackwell Scientific Publications, 1974; pp. 24-46.

29. Mead J. Dysanapsis in normal lungs assessed by the relationship between maximal flow, static recoil, and vital capacity. Am Rev Respir Dis 1980; 121: 339-342.

30. Taussig LM, Cota K, Kaltenborn W. Different mechanical properties of the lung in boys and girls. Am Rev Respir Dis 1981; 123: 640-643.

31. Hanrahan JP, Tager IB, Segal MR, et al. The effect of maternal smoking during pregnancy on early infant lung function. Am Rev Respir Dis 1992; 145: 1129-1135.

32. Hanrahan JP, Tager IB, Castile RG, Segal MR, Weiss ST, Speizer FE. Pulmonary function measures in healthy infants. Am Rev Respir Dis 1990; 141: 1127-1135.

33. Tepper RS, Reister T. Forced expiratory flows and lung volumes in normal infants. Pediatr Pulmonol 1993; 15: 357-361. 